\title{
The Global Flows of Metals and Minerals
}

By Donald G. Rogich and Grecia R. Matos

Open-File Report 2008-1355

U.S. Department of the Interior

U.S. Geological Survey 


\section{U.S. Department of the Interior DIRK KEMPTHORNE, Secretary}

\section{U.S. Geological Survey \\ Mark D. Myers, Director}

U.S. Geological Survey, Reston, Virginia: 2008

For product and ordering information:

World Wide Web: http://www.usgs.gov/pubprod

Telephone: 1-888-ASK-USGS

For more information on the USGS the Federal source for science about the Earth, its natural and living resources, natural hazards, and the environment:

World Wide Web: http://www.usgs.gov

Telephone: 1-888-ASK-USGS

Any use of trade, product, or firm names is for descriptive purposes only and does not imply endorsement by the U.S. Government.

Although this report is in the public domain, permission must be secured from the individual copyright owners to reproduce any copyrighted materials contained within this report.

Suggested citation:

Rogich, D.G., and Matos, G.R., 2008, The global flows of metals and minerals: U.S. Geological Survey Open-File Report 2008-1355, 11 p., available only online at http://pubs.usgs.gov/of/2008/1355/. 


\section{Contents}

Abstract
The Metals and Minerals Database
Trajectory of Global Metals and Minerals Flows.
Country Comparisons
Equity Consideration, per Capita Consumption, and Extraction/Consumption
Patterns
Use of Secondary Resources and Accretion in Stock
Outputs
Cuture Studies
Rencluding Remarks

\section{Figures}

1. World gross domestic product and world population ........................................................

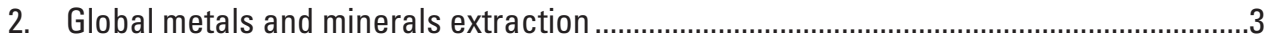

3. Global aluminum, copper, lead, and zinc consumption.....................................................

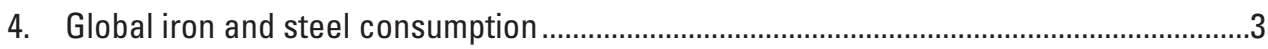

5. Global chromium and nickel consumption .......................................................................

6. Global extraction of toxic metals .............................................................................

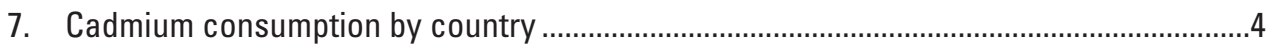

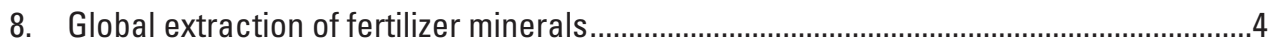

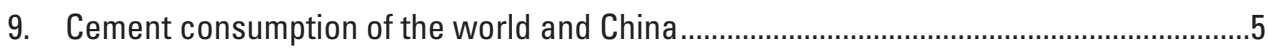

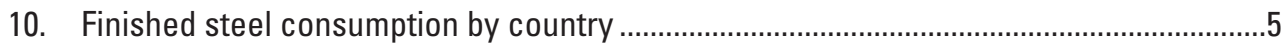

11. Copper consumption by country. ............................................................................

12. Aluminum consumption by country. ........................................................................

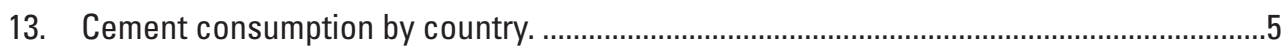

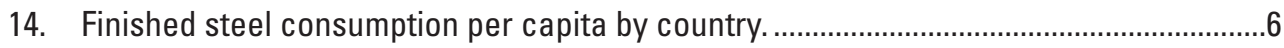

15. Copper consumption per capita by country.................................................................

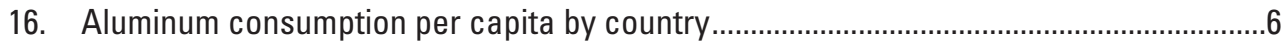

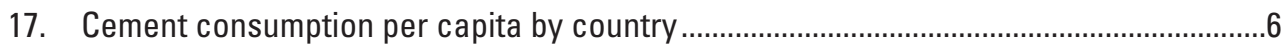

18. Consumption and extraction in the European Union group of 15 countries ......................7

19. Consumption and extraction in North America …….......................................................

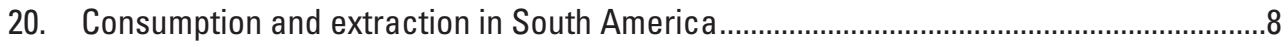

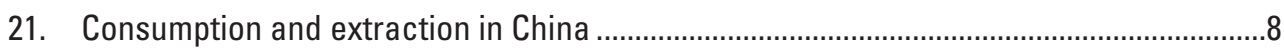

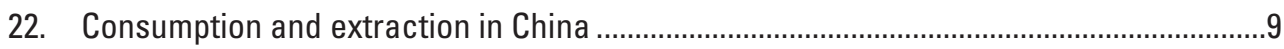



24. Graph illustrating calculated world metals recycling rates ..........................................10

25. Calculated world processing wastes for 12 selected mineral commodities....................10

26. Calculated world sulfur release from nonferrous smelting .............................................10 


\section{Tables}

1. Minerals and metals included in the global database ..................................................

2. Calculated world concentration and processing wastes for selected mineral commodities in 2004 


\title{
The Global Flows of Metals and Minerals
}

\author{
By Donald G. Rogich ${ }^{1}$ and Grecia R. Matos ${ }^{2}$
}

\section{Abstract}

This paper provides a preliminary review of the trends in worldwide metals and industrial minerals production and consumption based on newly developed global metals and minerals Material Flow Accounts (MFA). The MFA developed encompass data on extraction and consumption for 25 metal and mineral commodities, on a country-by-country and year-by-year basis, for the period 1970 to 2004. The database, jointly developed by the authors, resides with the U.S. Geological Survey (USGS) as individual commodity Excel workbooks and within a Filemaker data management system for use in analysis.

Numerous national MFA have been developed to provide information on the industrial metabolism of individual countries. These MFA include material flows associated with the four commodity categories of goods that are inputs to a country's economy, agriculture, forestry, metals and minerals, and nonrenewable organic material. In some cases, the material flows associated with the creation and maintenance of the built infrastructure (such as houses, buildings, roads, airports, dams, and so forth) were also examined. The creation of global metals and industrial minerals flows is viewed as a first step in the creation of comprehensive global MFA documenting the historical and current flows of all of the four categories of physical goods that support world economies.

Metals and minerals represent a major category of nonrenewable resources that humans extract from and return to the natural ecosystem. As human populations and economies have increased, metals and industrial minerals use has increased concomitantly. This dramatic growth in metals and minerals use has serious implications for both the availability of future resources and the health of the environment, which is affected by the outputs associated with their use. This paper provides an overview of a number of the trends observed by examining the database and suggests areas for future study.

\footnotetext{
${ }^{1}$ Retired from the U.S. Bureau of Mines as Division Chief of Mineral Commodities, 1995. Since then have served as a consultant on domestic and international material flows for a number of nonprofit, academic and government institutions.

${ }^{2}$ U.S. Geological Survey.
}

\section{The Metals and Minerals Database}

The current metals and minerals database includes data on the extraction, processing, and consumption for 25 mineral commodities ( 2 construction materials, 12 industrial minerals, and 11 metals) (table 1). Extraction data were obtained from U.S. Bureau of Mines and the USGS Minerals Yearbooks, supplemented by information from USGS mineral commodity specialists, and the United Nations. Consumption data were obtained from a variety of sources, including publications from the British Geological Survey, Metallgeschellschaft, and the United Nations, along with information provided by the European Cement Association (Cembureau) and the International Fertilizer Institute. While extraction information is complete for all mineral commodities, consumption data were not available for several commodities. Available information permitted data to be included for almost 200 individual countries in the world. It is important to note that consumption data are for the first point of consumption; ultimate consumption in the form of manufactured products could be significantly different.

Data were initially compiled in Excel spreadsheets and subsequently loaded into the Filemaker relational database management system. Data quality for most countries was felt to be fairly consistent for all commodities, with the exception of the large gravel and crushed stone, and sand, silica, and quartz flows, which are considered less reliable owing to underreporting by many developing countries.

One of the issues involved in the creation of the metals and minerals database, and probably global MFA for other groups of commodities, is the declining availability of data and restrictions on its use. As reported by the National Research Council, the need for more frequent and detailed analyses of some critical minerals is at present more acute due to the highly global nature of the mineral market and increased global competition for mineral resources (National Research Council, 2008, p. 172). Globally, metal and minerals information gathering and dissemination appear to be declining, resulting in a decrease in the coverage and availability of critical data. A recent report from the World Resources Institute also states that conventional economic accounts do not systematically track the movement of materials and energy into and out of the U.S. economy-from extraction to manufacturing, product use (and reuse or recycling), and eventual 
Table 1. Minerals and metals included in the global database.

[All data from 1970 through 2004, individually by country, in thousand metric tons]

\begin{tabular}{|c|c|c|}
\hline Commodity & Extraction and production data & Consumption data \\
\hline \multicolumn{3}{|c|}{ Construction materials } \\
\hline Gravel and crushed stone & Extraction & Consumption data not available. \\
\hline \multicolumn{3}{|c|}{ Industrial minerals } \\
\hline Asbestos & Extraction of asbestos units & Consumption of asbestos units. \\
\hline Cement & Production & Consumption. \\
\hline Clay & $\begin{array}{l}\text { Extraction of bentonite, fullers earth, kaolin, } \\
\text { and common clay }\end{array}$ & Consumption data not available. \\
\hline Fluorspar & Extraction of $\mathrm{CaF}_{2}$ units & Consumption of $\mathrm{CaF}_{2}$ units. \\
\hline Potash & Extraction of $\mathrm{K}_{2} \mathrm{O}$ units & Consumption as fertilizer of $\mathrm{K}_{2} \mathrm{O}$ units. \\
\hline Salt & Extraction of salt units & Consumption of salt units. \\
\hline Soda ash & Extraction $\mathrm{NaCO}_{3}$ units & Consumption data not available. \\
\hline Sulfur & $\begin{array}{l}\text { Extraction/production pyrites, metallurgy, } \\
\text { petroleum }\end{array}$ & Consumption of sulfur units. \\
\hline \multicolumn{3}{|c|}{ Metals } \\
\hline Aluminum & Extraction of bauxite units & $\begin{array}{l}\text { Consumption of primary, secondary, and } \\
\text { total aluminum metal. }\end{array}$ \\
\hline Gold & Extraction of gold units & Consumption data not available. \\
\hline Iron and steel & Extraction of iron ore, finished steel & Consumption of finished steel. \\
\hline Lead & Extraction of lead units & Consumption of lead units. \\
\hline Mercury & Extraction of mercury units & Consumption of mercury units. \\
\hline Nickel & Extraction of nickel units & Consumption of nickel units. \\
\hline Zinc & Extraction of zinc units & Consumption of zinc units. \\
\hline
\end{tabular}

disposal. This failure makes it more difficult to gauge the full economic costs and benefits (including associated environmental consequences) of the energy and materials used to provide goods and services. As a result, public policies and private actions are based on an incomplete, perhaps seriously misguided, understanding of the true costs of production (World Resources Institute, 2008).

Moreover, a U.S. interagency working group on industrial ecology and materials and energy flows states that because the substitution of one material for another can take decades, long-term collection of a set of core statistics is critical to our understanding of materials cycles and shifts in both materials production and demand (U.S. Interagency Working Group on Industrial Ecology, Material, and Energy Flows, 1999). The reduced availability of public information sources impedes or prohibits data gathering and inhibits the creation of holistic MFA vital for policy considerations. 


\section{Trajectory of Global Metals and Minerals Flows}

While the database permits the examination of individual metal and mineral commodities and countries singly or in any combination, this paper discusses only selected commodity and country examples to illustrate some of the analytic possibilities. The underlying factors driving the trends observed below are considered appropriate subjects for future study and no attempt has been made to do so comprehensively, other than to describe what has taken place.

During the 35-year period examined (1970-2004), world population and gross domestic product (GDP), as measured in constant 2000 U.S. dollars, increased by about 72 and 225 percent, respectively (fig. 1).

Simultaneously, the global extraction of major metals grew by over 75 percent, industrial minerals by 53 percent, and construction materials by 106 percent (fig. 2). The authors observed that data for construction material extraction were not reported by some countries.

The global consumption of aluminum, copper, lead, and zinc during the 35-year period are shown individually (fig. 3). Aluminum consumption increased by more than three times, the most dramatic increase of the nonferrous metals, while copper and zinc consumption increased about twofold. Lead consumption increased the least during the period, about one and a half times.

Ferrous metals are used in the production of steel. Global consumption of steel (fig. 4) increased slowly until the late 1990s, after which it started to increase rapidly to about one billion tons per year, about twice the 1974 level.

The leading use for chromium and nickel is in the production of stainless steel. Global chromium and nickel consumption (fig. 5) rates increased by factors of nearly 2 and 0.75 , respectively, similar to the rise in steel consumption; however, neither show the rapid increase in consumption that steel experienced from the late 1990s to 2004, largely due to the increased demand from China in recent years. It should be noted that the metals data shown include consumption from primary and secondary (metal recovered from scrap by remelting and refining) resources.

Toxic metals are of particular concern as their release into the environment, even in small quantities, can result in longterm negative impacts on living species. The global extraction of three metals considered to be toxic is shown in figure 6. Arsenic data exhibited significant fluctuations during the period and perhaps an overall rise. The extraction of mercury declined significantly during the period, and cadmium extraction was relatively flat. Despite relative constant extraction of cadmium, the locations of extraction and initial consumption have shifted to where products containing cadmium are manufactured.

Comparing the United States with China, India, and Japan, figure 7 shows that U.S. consumption of cadmium has declined; Japanese consumption increased rapidly begin-

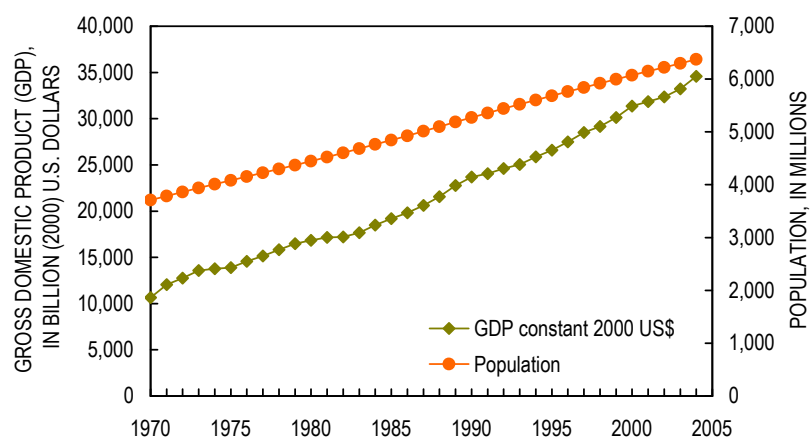

Figure 1. World gross domestic product (GDP) (constant 2000 U.S. \$) and world population. [Source: U.S. Census Bureau, International Database (2007), and The World Bank, World Development Indicators Database (2007).]

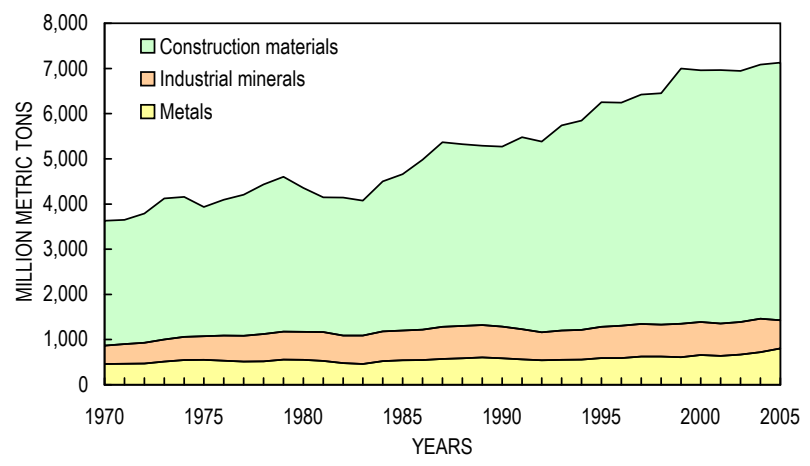

Figure 2. Global metals and minerals extraction.

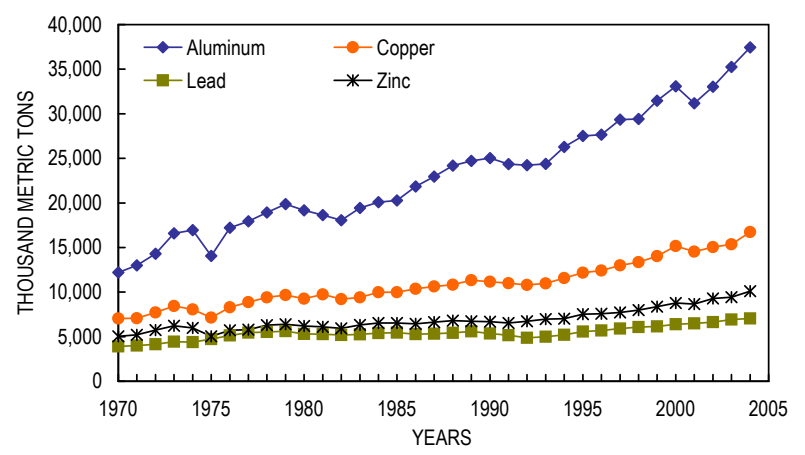

Figure 3. Global aluminum, copper, lead, and zinc consumption.

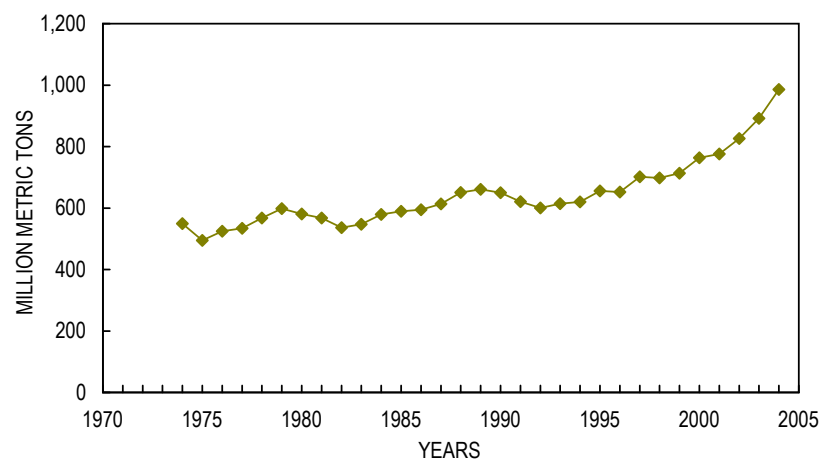

Figure 4. Global iron and steel consumption (finished steel). 


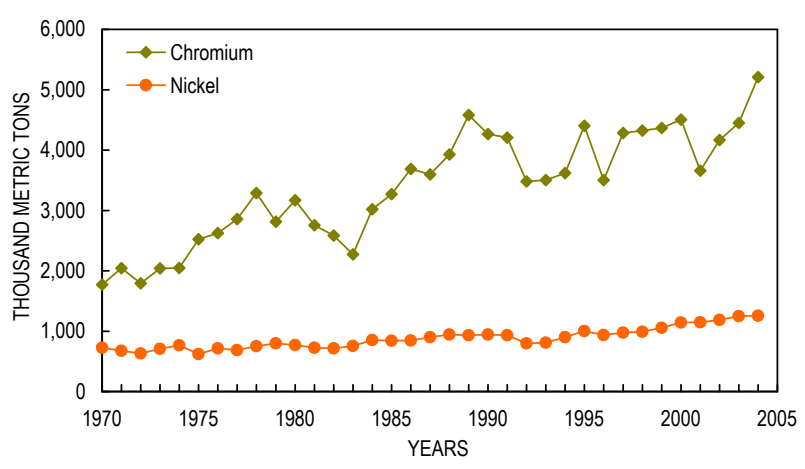

Figure 5. Global chromium and nickel consumption.

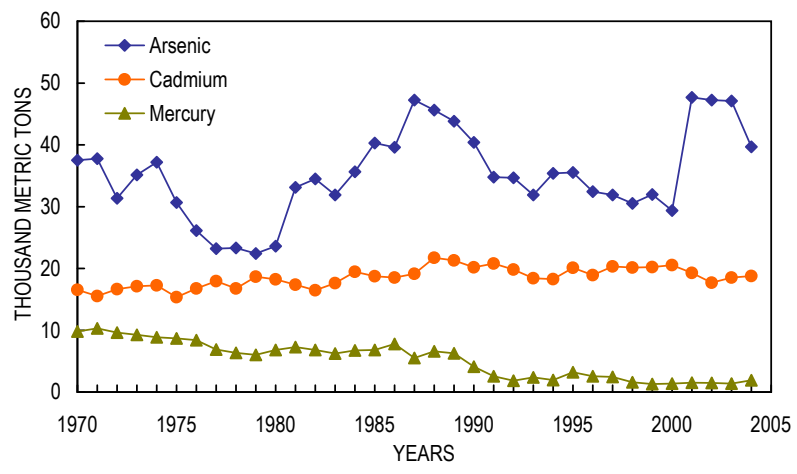

Figure 6. Global extraction of toxic metals.

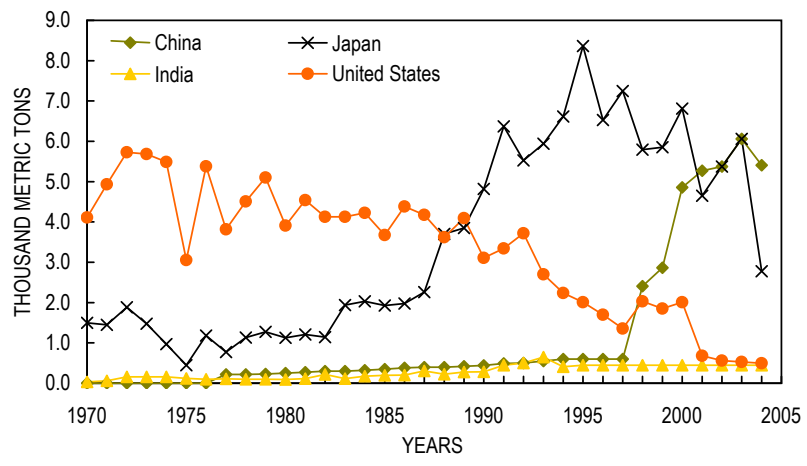

Figure 7. Cadmium consumption by country.

ning in 1985 and then declined rapidly after 1995. Chinese consumption was low until 1997, after which it grew rapidly. Where final consumption and consequent disposal take place might indicate an entirely different story because by 2005 more than 80 percent of the cadmium used in the United States was contained in batteries, mostly in rechargeable nickelcadmium $(\mathrm{NiCd})$ batteries used in popular consumer products such as cordless phones and power tools (Wilburn, 2007). What has apparently transpired is that while the United States has substantially cut back on the primary consumption of cadmium and the manufacture of associated products, imports of products containing cadmium, such as $\mathrm{NiCd}$ batteries, have increased. While we have avoided the health issues associated with manufacture, we still have a significant problem with respect to the disposal of these products. The amount of cadmium metal contained in imported products in 2004 was estimated to be about 3,000 metric tons, or about three times the reported cadmium production in the United States from all primary and secondary sources. As much as 11 percent of this material was recycled, and the balance was placed in municipal solid waste landfills (Wilburn, 2007). The pattern of Japanese consumption reflects an intensive production of $\mathrm{NiCd}$ batteries to 1995, after which time the cadmium consumption decreased markedly as a result of a shift in production of nickel metal hydride batteries and lithium ion batteries, which have better performance and recharging capabilities.

Figure 8 displays the global extraction of the fertilizer minerals nitrogen $(\mathrm{N})$, phosphate $\left(\mathrm{P}_{2} \mathrm{O}_{5}\right)$, and potash $\left(\mathrm{K}_{2} \mathrm{O}\right)$ during the period 1970-2004. Extraction has been shown in lieu of consumption since the only consumption data available were for the use of these minerals as fertilizer, and it is estimated that this understates the total consumption of these commodities on the order of 10-20 percent. The growth in consumption of phosphate and potash was high early in the period and then remained essentially level from 1980 onward. Nitrogen extraction represents a dramatically different situation where 2004 extraction is roughly four times the amount in 1970. This increase may be due more to an underreporting by China in the early years than to an actual increase (Kramer, D.A., U.S. Geological Survey, oral commun., 2008).

Construction materials (sand and crushed stone) represent the bulk of mineral commodities on the basis of weight. Cement, a derivative of these and other components, also represents a large manufactured material flow. Data on cement production and consumption most likely capture the vast majority of global cement production and consumption; data for gravel and crushed stone and sand, silica, and quartz are less complete. This is owing to the fact that in undeveloped countries, materials such as crushed stone and sand may never enter the formal economy and be captured by a minerals reporting system. If this supposition is correct, then the extraction and consumption of these minerals will accordingly be understated. The global consumption of cement rose fourfold during the period and now exceeds 2 billion tons per year; currently, China accounts for almost one half of this amount (fig. 9).

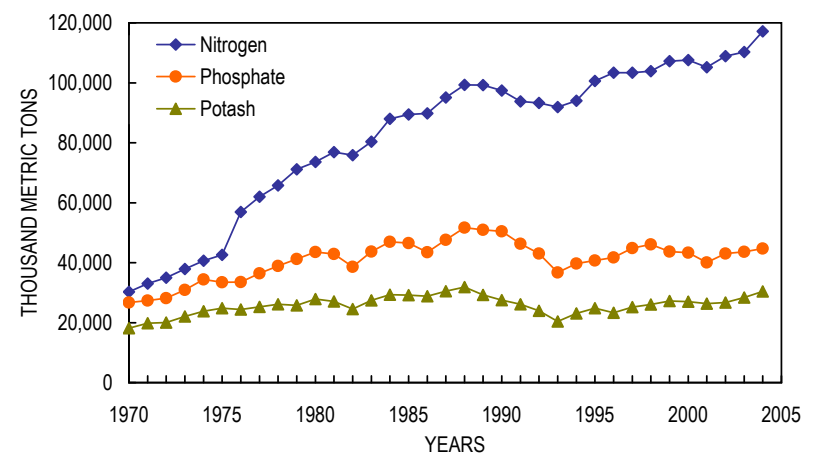

Figure 8. Global extraction of fertilizer minerals. 


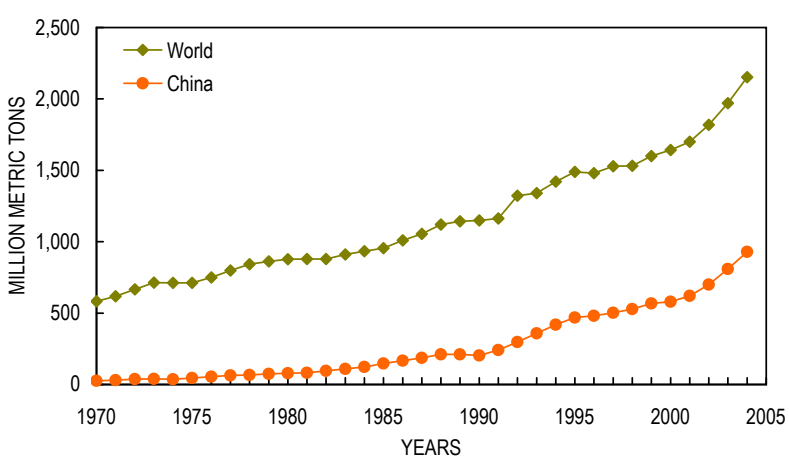

Figure 9. Cement consumption of the world and China.

\section{Country Comparisons}

Figures 10-13 display the consumption trends for selected commodities for China, the European Union group of 15 countries (EU-15), India, the Republic of Korea, and the United States. These graphs show the dramatic rise in consumption in China as its economy developed. This trend stands in contrast with the rather slower and intermittent growth of the United States and EU-15 where a higher stage of development was achieved earlier. While consumption of steel, copper, aluminum, and cement in China increased modestly from 1970 to about 1995, subsequent to that period, consumption grew very rapidly. Currently, China consumes about one-half of the world's annual production of cement and 25 percent of the world's steel. While the growth in consumption of these commodities was also high for India and the Republic of Korea, the absolute quantities consumed are small compared with China.

\section{Equity Consideration, per Capita Consumption, and Extraction/ Consumption Patterns}

An examination of the rates of consumption per capita provides a somewhat different picture than that portrayed by considering absolute material flows. Per capita consumption rates for aluminum, copper, steel, and cement were examined for China, the EU-15, India, the Republic of Korea, the United States, and the world as a whole for the period 1970-2004 (figs. 14-17). The first observation in the per capita analysis is the rapid increase in per capita consumption of these commodities by the Republic of Korea. High growth rates existed for all four commodities due to rapid industrialization up until the Asian financial crisis at the end of 1997. The economy of the Republic of Korea focused on heavy industry and automotive production during the 1970s and 1980s, which required intensive use of steel, copper, and aluminum. Later, the electronics, telecommunications, motor vehicle, shipbuilding,

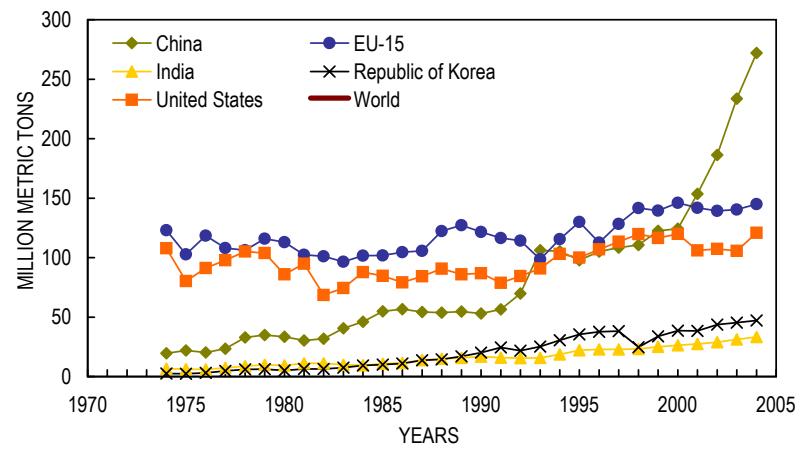

Figure 10. Finished steel consumption by country.

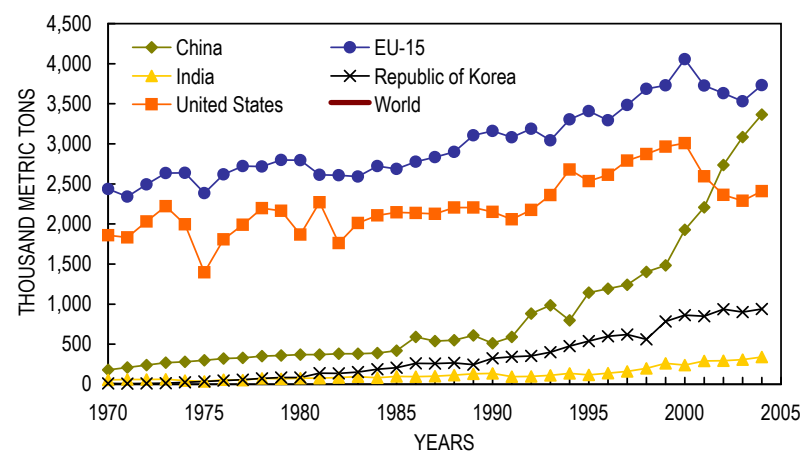

Figure 11. Copper consumption by country.

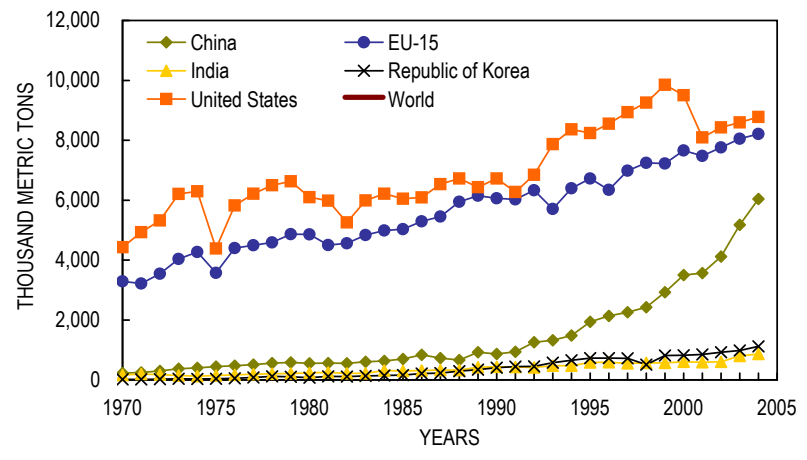

Figure 12. Aluminum consumption by country.

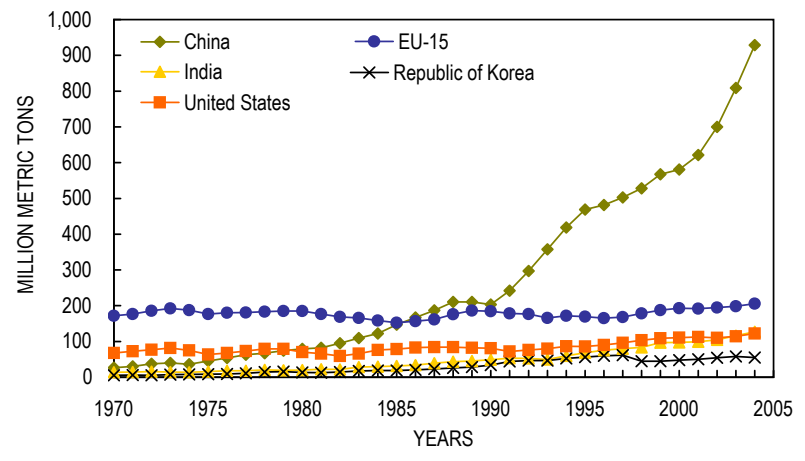

Figure 13. Cement consumption by country. 


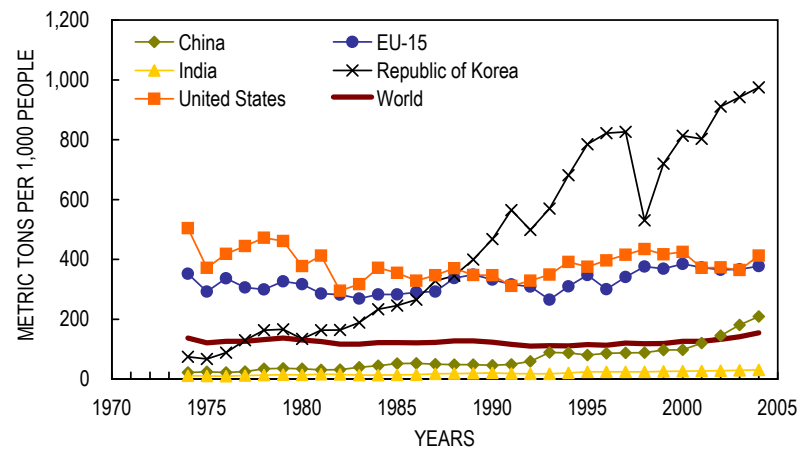

Figure 14. Finished steel consumption per capita by country.

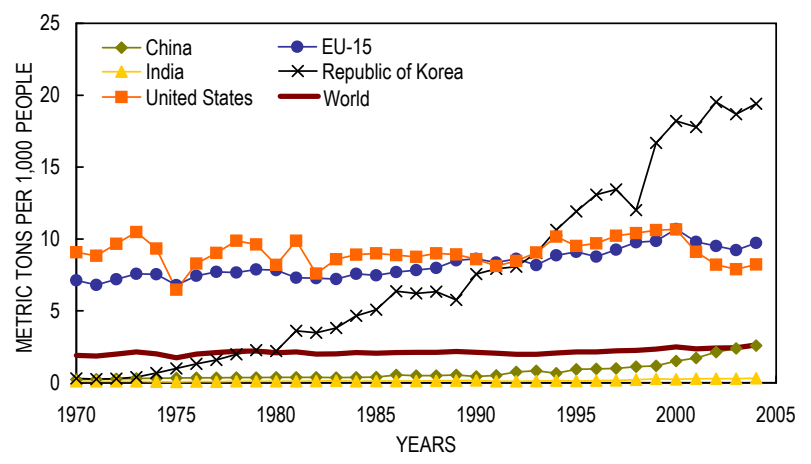

Figure 15. Copper consumption per capita by country.



Figure 16. Aluminum consumption per capita by country.

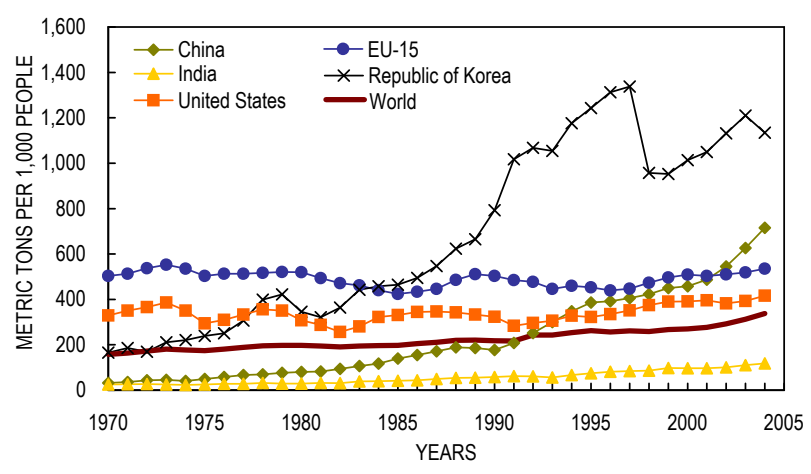

Figure 17. Cement consumption per capita by country. mining and manufacturing, petrochemical, industrial machinery, and steel industries expanded, with the Republic of Korea surpassing every country in the consumption per capita of steel and copper and exceeding all but the United States in the per capita consumption of aluminum (U.S. Central Intelligence Agency, 2008). Cement production was an important industry during the Republic of Korea's period of rapid growth, mainly owing to strong domestic demand by the construction industry (fig. 17).

For the metals, it can be seen that the Chinese per capita rate of consumption has grown considerably faster than that of India but is still considerably lower than that of the United States and the EU-15. China's consumption per capita of each of the three metals by 2004 approaches, or exceeds, the worldwide average. For cement, China now has a higher per capita consumption than that of the EU-15 and the United States. Comparing the EU-15 and the United States shows that steel consumption per capita in the United States declined slightly during the period while that for the EU-15 countries increased slightly. With respect to copper, the EU-15 consumption per capita now exceeds that for the United States. Aluminum per capita consumption rates for the United States and the EU-15 both grew during the period, but the United States rate of per capita aluminum consumption remained higher than that of the EU-15. Cement per capita consumption in the EU-15 remained higher than that in the United States, although the gap appears to be closing somewhat. Overall, global per capita cement consumption rose considerably, driven to a large degree by China and India.

In general, a considerable gap continues to exist between the per capita consumption of developed countries, such as the EU-15 and the United States, and the world as a whole. While GDP grew by about 225 percent, as mentioned previously, the gap in the per capita consumption rates between the developed and developing countries, as far as the main metal inputs to economies is concerned, does not appear to have closed. Additionally, it is important to reiterate that the metal consumption discussed is the first point of use in the economic system. While much of the steel and almost all of the cement consumption goes to the creation of the built infrastructure within the consuming country, significant portions of the copper and aluminum consumed end up in manufactured goods, many of which are ultimately used and disposed of in other countries. An example of this is the final consumption of automobiles in the United States and NiCd batteries as previously discussed.

\section{Global Extraction and Consumption Patterns}

During the period examined, there appears to have been a marked shift in where metal and mineral commodities are extracted and where they are consumed. Figures 18-23 examine the extraction and consumption pattern for base 

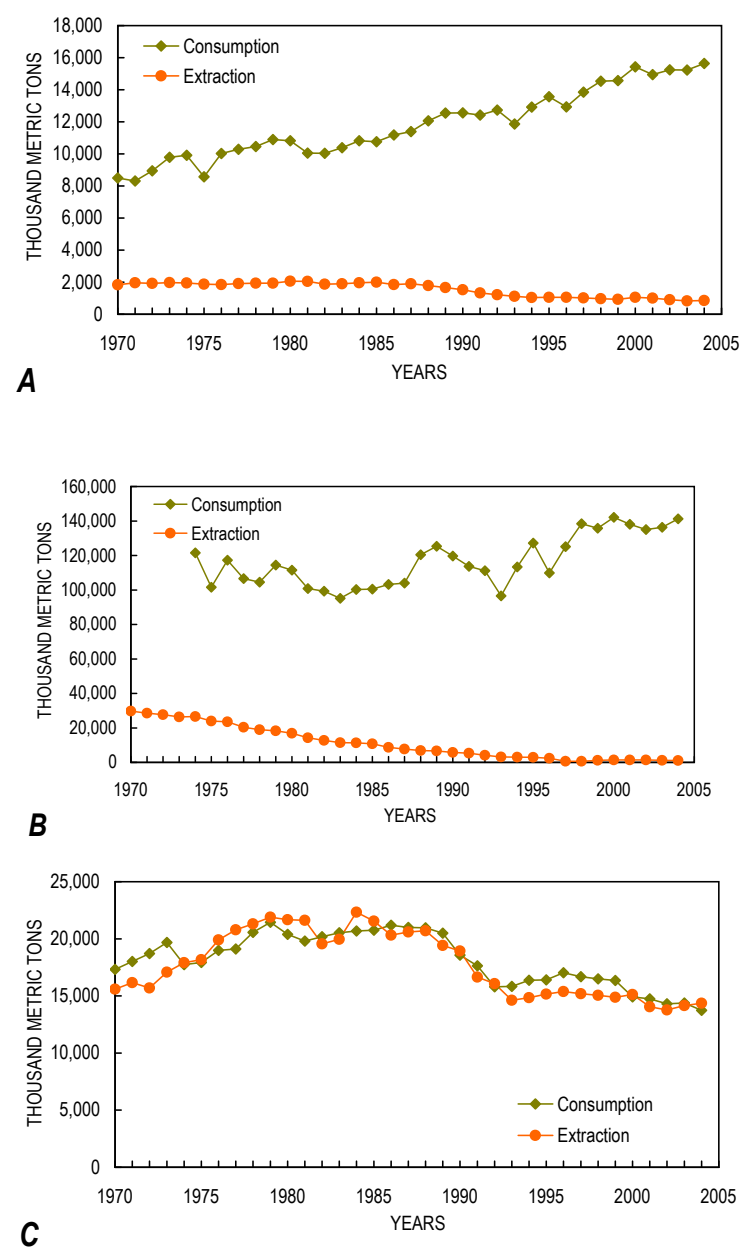

Figure 18. Consumption and extraction in the European Union group of 15 countries (EU-15). A, Base metals. B, Iron and steel. C, Nitrogen, phosphorus, and potassium (NPK).

metals (aluminum, copper, lead, and zinc), iron and steel, and the fertilizer minerals (nitrogen, phosphate, and potash) for six countries/regions of the world. In North America (Canada, the United States, and Mexico) and the EU-15, the gap between consumption and extraction of base metals and iron and steel is widening - more material is consumed than extracted. This relationship is different for the fertilizer minerals. Extraction and consumption are nearly equal in the EU-15, and in North America, more fertilizer minerals are extracted than consumed. For Japan and the Republic of Korea combined, consumption of each of the three commodity groups is greater than extraction. China exhibits increasing consumption versus extraction relative to the two metal categories and nearly equal extraction and consumption of fertilizer minerals. The trends for India are the inverse of most other examples-greater extraction than consumption of the metal categories and a widening gap between consumption and extraction of fertilizer minerals. The South American countries, along with other regions not examined in this paper, are playing a major role in filling the consumption/extraction gap for the two metal categories in the developed countries and increasingly in
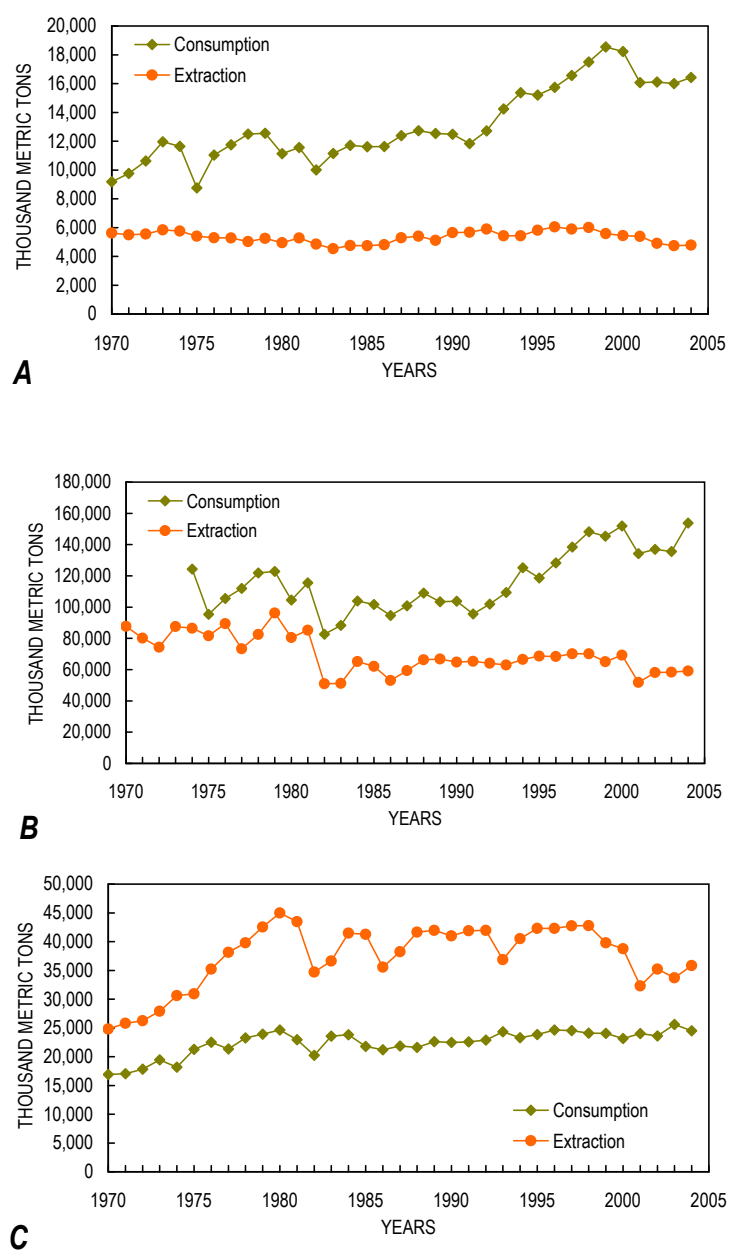

Figure 19. Consumption and extraction in North America. A, Base metals. B, Iron and steel. C, Nitrogen, phosphorus, and potassium (NPK).

China. Because the ancillary outputs associated with the extraction and initial processing of commodities can create considerable environmental impacts, particularly where the most advanced technology is not employed; the trends observed raise concerns about the environmental pressures in the extractive regions.

\section{Use of Secondary Resources and Accretion in Stock}

Metal and mineral commodities are nonrenewable resources, and therefore their total availability, while not readily definable, is finite. In this context, mechanisms that serve to reuse or recycle these materials increase long-term sustainability. Figure 24 displays the estimated percentage of world steel, aluminum, copper, and lead obtained from secondary sources. This percentage was obtained by calculating the difference between the global extracted metal content 

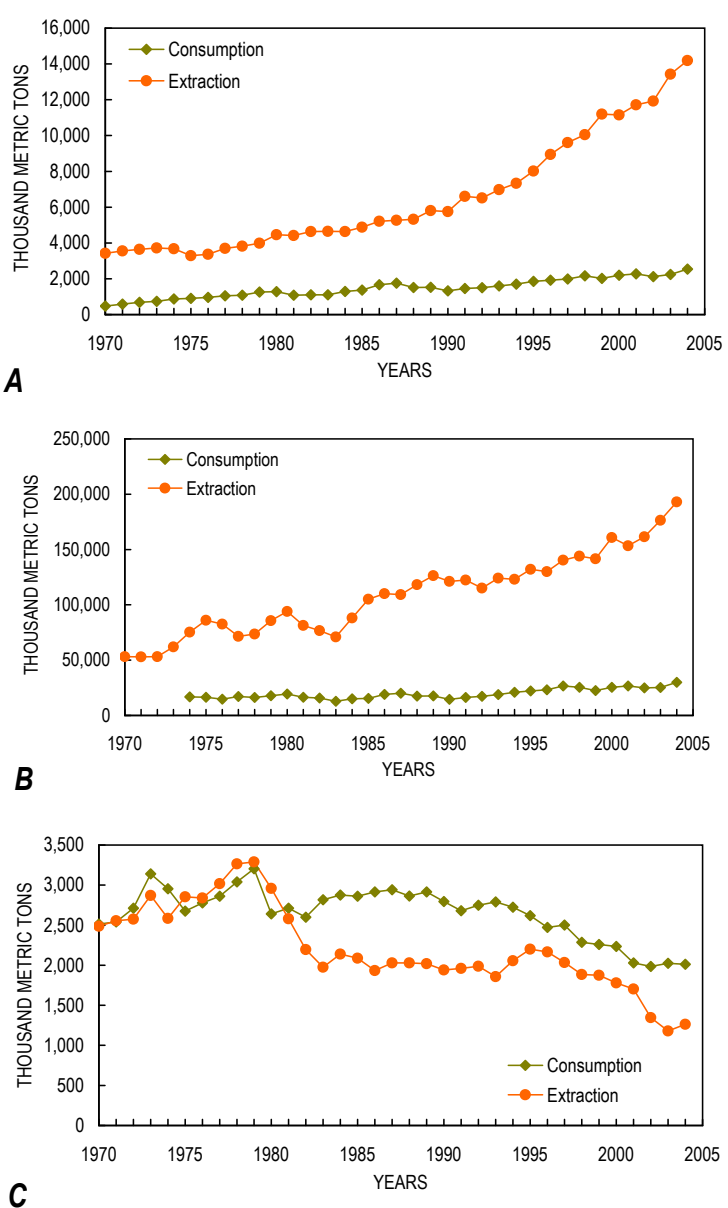

Figure 20. Consumption and extraction in South America. A, Base metals. B, Iron and steel. C, Nitrogen, phosphorus, and potassium (NPK).

of steel, aluminum, copper, and lead and world consumption for individual years. Except for lead, used predominantly in lead acid batteries for which well-organized collection and recycling procedures have been established, the trends are not particularly encouraging. Although, steel recycling appears to be increasing from a plateau of less than 20 percent, the use of secondary copper currently appears to be only a little greater than 10 percent by 2004, and aluminum recycling rates ranged between 20 and 30 percent during the entire period.

Increasing the use of secondary resources represents a considerable challenge with respect to nonrenewable metal and industrial mineral resources. Although large amounts of construction minerals, including sand, gravel, and crushed stone, are consumed, they are relatively plentiful in most regions and therefore only small amounts are reused. A number of mineral commodities, such as fertilizer minerals, salt, and other industrial minerals, are used in a dissipative manner such that recycling is impossible. A large percentage of the metals commodity flow ends up in addition to the built infrastructure where they remain with the current design of most products for a long time, before they are available for reuse. Some metal flows end up in complex products that inhibit
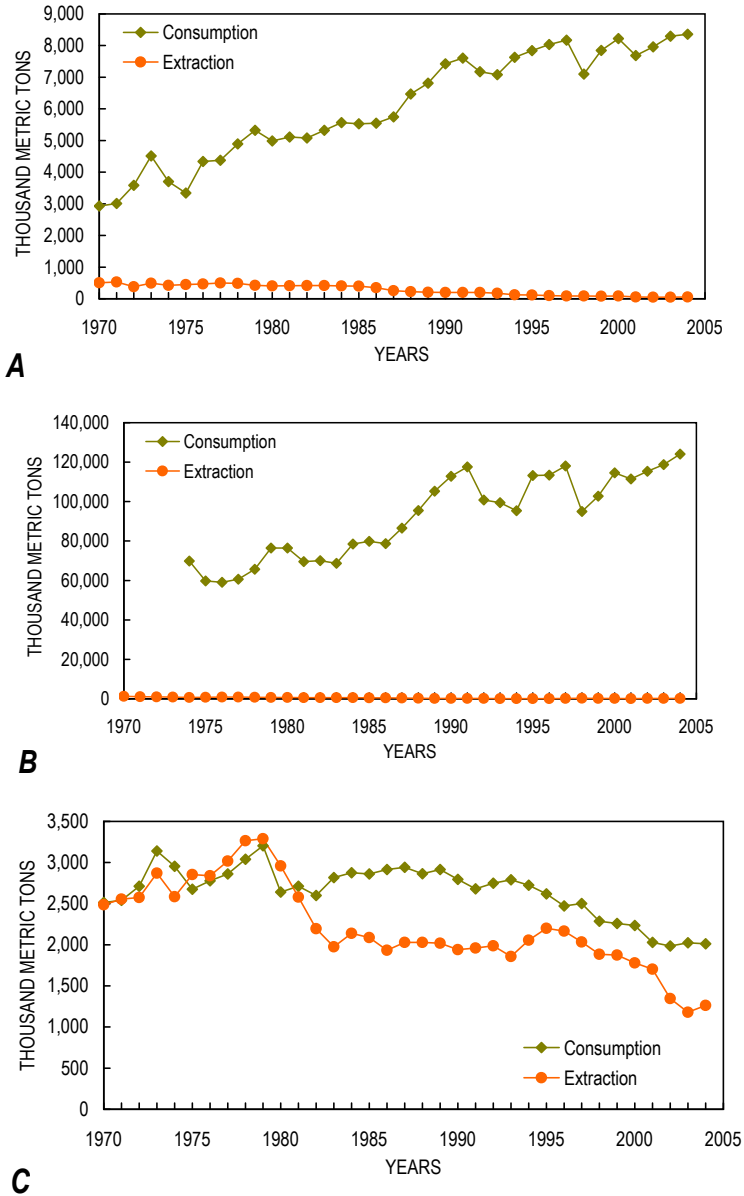

Figure 21. Consumption and extraction in Japan and the Republic of Korea. A, Base metals. B, Iron and steel. C, Nitrogen, phosphorus, and potassium (NPK).

recycling. As populations and the supporting infrastructure increase, the amount of material tied up in these applications is likely to increase.

\section{Outputs}

Outputs (releases) to the environment take place at every stage of metal and mineral extraction, processing, use, and disposal where they cause environmental disturbance and, in a number of cases, severe impacts. Unless recycled, all metal and mineral flows, except those that become part of a longterm built infrastructure, ultimately exit the economy either rapidly, as in the case of fertilizer and chemicals, or after a period of time, for those uses associated with durable consumer goods. Because, on a tonnage basis, the largest flows are those associated with construction of long-term infrastructure, the percentage of commodity inputs that exit quickly to the environment is small. In 2000, the percentage of metals and minerals inputs that exited the U.S. economy after less 


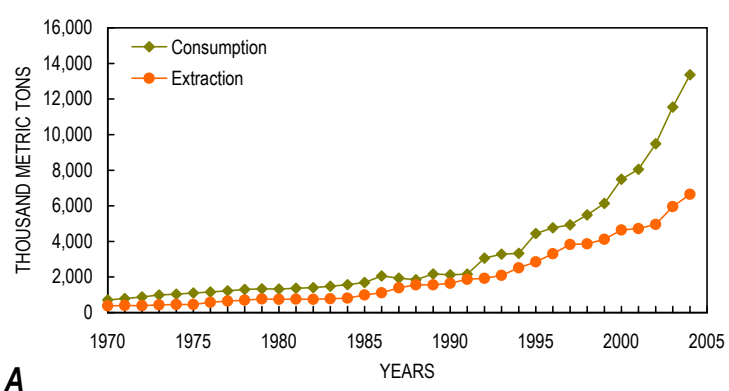

A
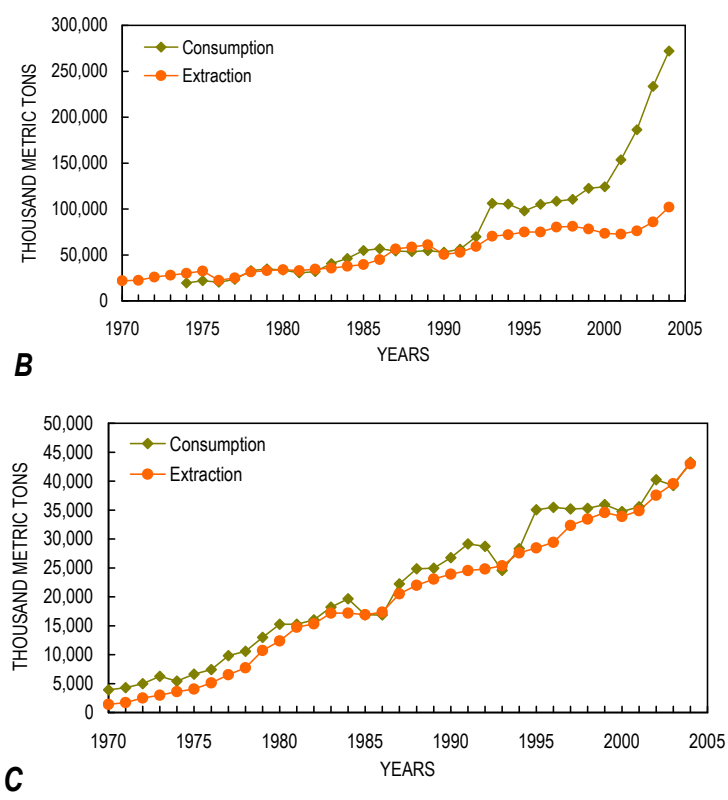

Figure 22. Consumption and extraction in China. A, Base metals. B, Iron and steel. C, Nitrogen, phosphorus, and potassium (NPK).

than 30 years in use was estimated to be about 10 percent (World Resources Institute, 2000).

Commodity flows represent only a portion of the material mobilized as part of the minerals cycle. The ancillary, or hidden, material flows associated with extraction, concentration, and processing constitute far greater quantities than the commodities for many commodity flows. These ancillary flows are comprised of the overburden removed during mining and quarrying and the nonvalue minerals and materials separated from the product during the concentration and processing stages. Estimates of the amount of overburden or mine rock removed to gain access to the mineralized material are very site specific and estimating worldwide quantities would be extremely tenuous. A calculation of concentration and processing waste can be made based on estimates of worldwide average grade data. Table 2 provides estimates of the concentration and processing wastes associated with 12 metal and mineral commodities in 2004. While there is considerable variation from one commodity to another, the quantity of waste for all the commodities was calculated to be about four times the weight of the mineral commodities extracted, excluding overburden removal. It

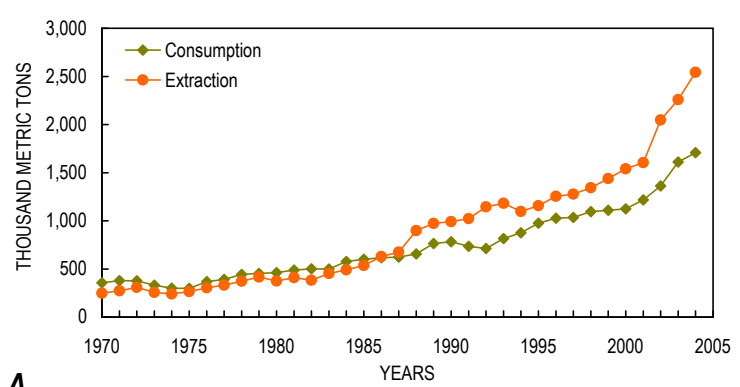

$A$
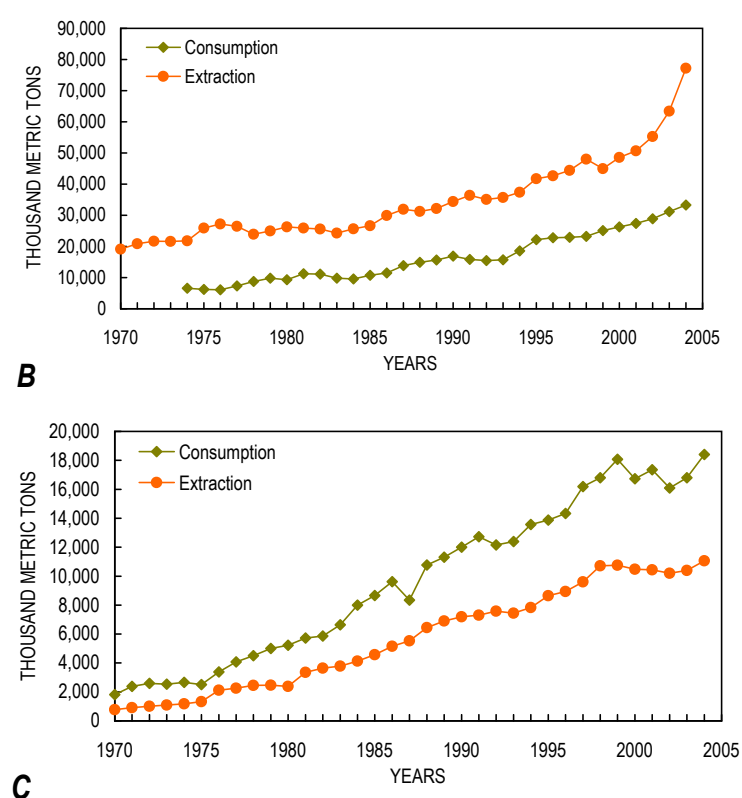

Figure 23. Consumption and extraction in India. A, Base metals. $B$, Iron and steel. C, Nitrogen, phosphorus, and potassium (NPK).

Table 2. Calculated world concentration and processing wastes for selected mineral commodities in 2004.

[In thousand metric tons]

\begin{tabular}{|c|c|}
\hline Commodities & 2004 \\
\hline Aluminum ............ & 129,100 \\
\hline Asbestos .................. & 61,770 \\
\hline Chromium .............. & 938 \\
\hline 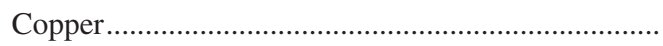 & $1,607,622$ \\
\hline Fluorspar ................ & 14,113 \\
\hline Gold.... & 485,998 \\
\hline 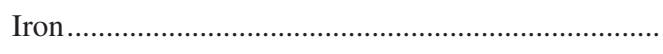 & 602,372 \\
\hline Lead.............. & 126,473 \\
\hline Mercury ................ & 254 \\
\hline Nickel.......... & 68,110 \\
\hline Phosphate ............ & 96,400 \\
\hline Zinc ................ & 170,175 \\
\hline Total processing waste .... & $3,372,325$ \\
\hline
\end{tabular}




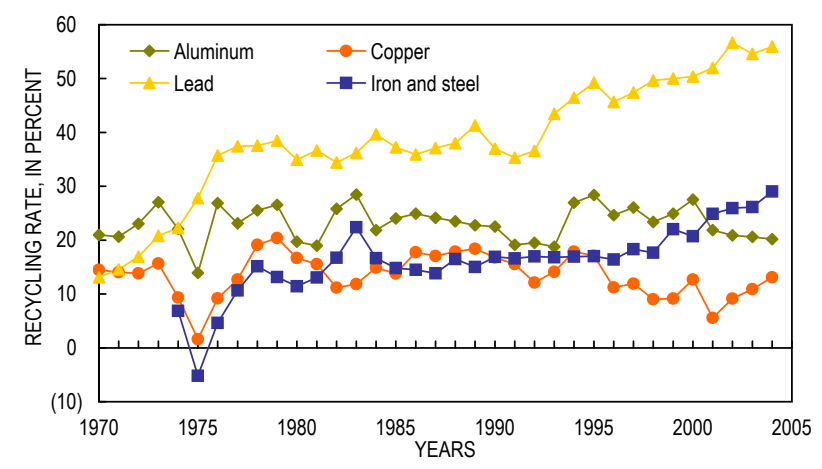

Figure 24. Graph illustrating calculated world metals recycling rates.

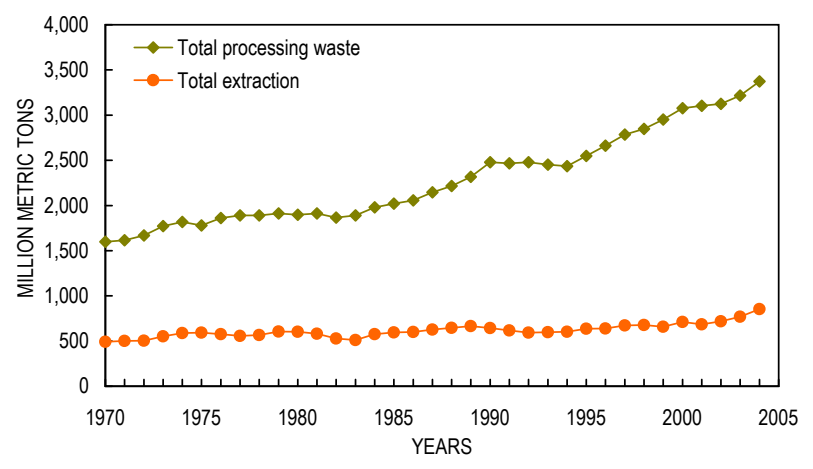

Figure 25. Calculated world processing wastes for 12 selected mineral commodities.

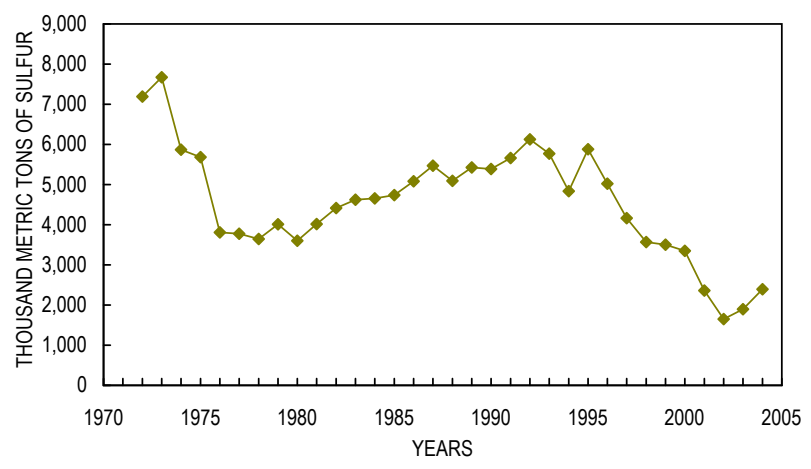

Figure 26. Calculated world sulfur release from nonferrous smelting, excluding nickel sulfide ores.

also exceeded 3 billion tons globally that year, a significant quantity considering that much of this waste is far from benign in its potential effects on the environment, including human health. Figure 25 displays the relationship between commodity extraction and waste flows over time. The waste flow increases faster than the commodity extraction during the period displayed, owing mainly to declining ore grades.

One of the processing wastes historically shown to create significant environmental impacts is the sulfur released during the processing of nonferrous ores. Based on a calculation of the sulfur contained in the principal copper, lead, and zinc ores and on data on the global quantities of sulfur captured from metallurgical operations, a rough calculation of the amounts released to the environment can be made. While admittedly imprecise, the increasing percentage of sulfur captured during the period is encouraging (fig. 26).

\section{Future Studies}

This paper illustrates the type of information that can be gleaned from the global metal and industrial minerals MFA and highlights some of the trends observed. Investigating the factors driving the trends discussed will help identify causation and assess possible future trajectories.

For certain critical commodities, there is clearly a need to evaluate the current trends in relation to sustainability. Additionally, what are the global environmental implications of the material trends observed? China is already suffering severe pollution problems resulting from the vast material flows it has mobilized and some of these have overflowed its boundaries (New York Times, 2007). Additionally, further investigation of globalization, the transfer of goods and burdens, and the relationship of individual countries within the global framework will help determine the relationships between physical flows, economic growth, and individual well-being.

Future maintenance of the metal and minerals database is important, and the addition of other commodities, particularly those associated with alternative energy and high-tech applications, will enhance the utility of this database. Most importantly, the creation of a comprehensive global MFA would encompass all the agricultural, forestry, and nonrenewable organic material flows, in addition to the metal and mineral flows developed to date. While global economic accounts are well developed, we live in a physical world in which physical material accounts will permit understanding of the limits and opportunities of the Earth.

\section{Concluding Remarks}

Global flows of almost all of the metal and industrial mineral commodities examined increased considerably during the time period. The continuation of these trends is problematic from a long-term perspective and, on a commodity-bycommodity basis; it could eventually be slowed by issues of scarcity or unacceptable environmental impacts associated with the use and outputs of the commodity. Simultaneously, several other trends are evident from the data. The first is that global equity, as implied by commodity consumption per capita, does not appear to have improved, in spite of the rising material flows. Secondly, the environmental burden associated with extraction and processing seems to be increasingly borne by the lesser developed countries. These trends combine to create a situation that is not sustainable for the long term, unless we are able to increase recycling, reuse, and remanufac- 
turing; significantly reduce the amount of materials used; or reduce environmental releases. If populations continue to grow as expected, the creation of new industrial models may help to increase recycling inputs and decrease outputs.

Finally, examining the material flows associated with metals and minerals tells only part of the story; thus, compiling the material flows associated with the other major commodity groups in a similar fashion may be a useful undertaking. In a finite world, a holistic and detailed understanding of the physical flows of the materials mobilized and transformed will be helpful to the creation and maintenance of a sustainable industrial economy.

\section{References Cited}

Kahn, Joseph, and Yardley, Jim, 2007, As China roars, pollution reaches deadly extremes: New York Times, August 26, 2007, p. 9.

National Research Council of the National Academies, 2008, Minerals, critical minerals, and the U.S. economy: Washington, D.C., National Research Council of the National Academies, Committee on Critical Mineral Impacts on the U.S. economy, Committee on Earth Resources, 264 p.

U.S. Census Bureau, 2007, International database: U.S. Census Bureau, accessed online July 20, 2007, at http://www.census.gov/ipc/www/idb/idbsprd.html.
U.S. Central Intelligence Agency, 2008, South Korea: World Factbook 2008, accessed online June 27, 2008, at https://www.cia.gov/library/publications/ the-world-factbook/print/ks.html.

U.S. Interagency Working Group on Industrial Ecology, Material and Energy Flows, 1999, Materials report: Washington, D.C., U.S. Interagency Working Group on Industrial Ecology, Material and Energy Flows, 29 p.

Wilburn, D.R., 2007, Flow of cadmium from rechargeable batteries in the United States, 1996-2005: U.S. Geological Survey Scientific Investigations Report 2007-5198, 34 p., accessed online at http://pubs.usgs.gov/sir/2007/5198/.

World Bank, 2007, World development indicators database:

The World Bank, accessed online July 20, 2007, at http://web.worldbank.org/WBSITE/EXTERNAL/DATASTAT ISTICS/O, contentMDK:20535285 menuPK:1192694 page PK:64133150 piPK:64133175 theSitePK:239419,00.html.

World Resources Institute, 2000, The weight of nationsMaterial outflows from industrial economies: Washington, D.C., World Resources Institute, 125 p.

World Resources Institute, 2008, Material flows in the United States; a physical accounting of the U.S. industrial economy: Washington, D.C., World Resources Institute, 42 p. 